\title{
CURRÍCULO EM ESCOLAS PÚBLICAS DE PERNAMBUCO: REFLEXÕES SOBRE AS MUDANÇAS NOS SÉCULOS XIX E XX
}

\author{
Leila Britto de Amorim Lima* \\ Telma Ferraz Leal ${ }^{* *}$
}

\begin{abstract}
Resumo: As concepções de linguagem, língua e de ensino e aprendizagem na prática escolar estão intrinsecamente vinculadas ao seu contexto histórico e ideológico. Nesse sentido, observar as propostas curriculares, em seu processo de produção, pode nos oferecer indícios de como o ensino de Língua Portuguesa estava sendo concebido nos séculos XIX e XX nos currículos. Este estudo procurou investigar o lugar da língua portuguesa nas propostas curriculares de Pernambuco nos séculos XIX e XX. A metodologia empregada neste trabalho consistiu na análise de conteúdo e documental (BARDIN, 2007), uma vez que a preocupação central foi o de interpretar os significados expressos nos documentos oficiais, ultrapassando uma simples compreensão do real para uma sistematização mais complexa dos dados apresentados. Os resultados evidenciaram que, apesar das propostas curriculares de Pernambuco passarem por mudanças em seus princípios teóricos e metodológicos ao longo do tempo, a maioria delas concebia a linguagem como expressão de pensamento e, consequentemente, o trabalho com a língua materna estava voltado para a decifração de palavras, frases ou textos e a priorização da arte do bem escrever. Foi no final do Século XX que mudanças mais substanciais ocorreram, com a adoção de uma perspectiva funcionalista.
\end{abstract}

Palavras-chave: Ensino. Língua Portuguesa. Currículo.

\begin{abstract}
Language meanings, language teaching and learning in school practices are related to the historical and ideological contexts. In this sense, a study about the elaboration processes of curricular proposals in a historical outlook can offer clues about how the language teaching has been designed in the nineteenth and the twentieth centuries. This study aimed to investigate how language has been seen in the curriculum of Pernambuco in these centuries. The methodology consisted of content analysis (BARDIN , 2007) because we intended to know the underlying meanings of official documents. In spite of the changes in theoretical and methodological principles in the curriculum of Pernambuco over time, the results showed that most of them presented language as an expression of thought. In this sense, language practices in the classroom involved a decoding process of word, sentence or texts as a way to develop writing process. The most relevant changes in the curriculum occurred in late twentieth century, when the functionalism theory was incorporated to language studies.
\end{abstract}

Keywords: Teaching. Language. Curriculum.

\section{Reflexões iniciais...}

As concepções de linguagem, língua, ensino e aprendizagem estão intrinsecamente vinculadas ao seu contexto histórico. Desse modo, as análises acerca das propostas curriculares em diferentes períodos da história podem nos oferecer indícios de como a língua portuguesa era concebida em cada momento. Neste artigo, enfocamos a análise das concepções de linguagem, língua e suas implicações no ensino de Língua Portuguesa nos séculos XIX e XX em Pernambuco.

A metodologia empregada foi baseada na análise de conteúdo e documental (BARDIN, 2004), uma vez que a preocupação central foi sobre o lugar da língua portuguesa nas propostas curriculares de Pernambuco séculos XIX e XX. A análise de conteúdo e documental nos permitiu interpretar os significados nos documentos oficiais.

\footnotetext{
" Mestre em Educação pela UFPE, técnica de ensino na Secretaria Estadual de Educação de Pernambuco. Endereço eletrônico: 1balima@ yahoo.com.br.

** Doutora em Psicologia, professora na graduação do curso de Pedagogia e na Pós-Graduação em Educação da Universidade Federal de Pernambuco. Endereço eletrônico: tfleal@ terra.com.br .
} 


\section{Concepções de linguagem e ensino de língua portuguesa: uma breve retrospectiva}

Estudos de Soares (1998) e Travaglia (1996) discutem sobre as principais concepções acerca da linguagem e suas implicações para o ensino de Língua Portuguesa. De forma geral, segundo esses autores, as concepções de linguagem perpassaram por três correntes distintas: linguagem como expressão do pensamento, instrumento de comunicação e processo de interação.

A primeira partia do pressuposto de que a capacidade de se expressar bem dependia da organização do pensamento, ou seja, o desenvolvimento da retórica estava articulado à forma como a linguagem se organizava e se estruturava na mente. Segundo Travaglia (1996, p. 21), "presume-se que há regras a serem seguidas para a organização lógica do pensamento e, consequentemente, da linguagem. São elas que se constituem nas normas do falar e escrever 'bem', (...)".

Já na segunda concepção, a linguagem era vista como instrumento de comunicação, pois se acreditava que os indivíduos utilizavam a língua para transmitir e compreender informações, ou seja, o texto era um objeto a ser interpretado e a compreensão dependia basicamente das habilidades do leitor de interpretar o que estava inscrito. Três elementos constituiriam o processo de comunicação: mensagem, emissor e receptor. Nesse contexto,

o ensino-aprendizagem da gramática e do texto, este considerado modelo da língua 'bem escrita', perde sua proeminência; (...): trata-se de desenvolver e aperfeiçoar os comportamentos do aluno como emissor/recodificador e como recebedor-decodificador de mensagens (...) (SOARES, 1998, p. 57).

A concepção mais recente toma a linguagem como processo de interação, ou seja, a linguagem é lugar da interação humana, dotada de historicidade e ideologicamente implicado. Começam a ser postas em destaque, com base nesta concepção, as condições de produção do discurso. Tratou-se da ênfase que passou a ser dada aos efeitos de sentido produzidos pelos interlocutores num determinado contexto sócio-histórico.

Bakhtin (2000), um dos principais defensores dessa ideia, destaca que "o emprego da língua efetua-se em forma de enunciados (orais e escritos) concretos e únicos, proferidos pelos integrantes desse ou daquele campo da atividade humana" (BAKHTIN, 2000, p. 261). Nesse sentido, no próximo item, discutiremos como as concepções de linguagem estavam sendo materializadas nos currículos em foco.

\section{Um olhar sobre os currículos de Pernambuco}

Segundo Soares (2003), referenciando os estudos de Cunha (1985), o ensino da Língua Portuguesa, no Brasil, de forma mais institucionalizada e continuada, é bastante recente:

Até meados do Século XVIII, no sistema de ensino do Brasil (como no de Portugal), o ensino do português restringia-se à alfabetização, após a qual os alunos passavam diretamente à aprendizagem do latim, ou melhor, da Gramática da língua latina. Quando a Reforma Pombalina (1759) tornou obrigatório, em Portugal e no Brasil, o ensino da Língua Portuguesa, esse ensino seguiu a tradição do ensino do latim, isto é, definiu-se e realizou-se como ensino da gramática do português [...]. 
Britto (2005), em seus estudos, discute sobre a trajetória do currículo de Ensino Fundamental na rede estadual de Pernambuco. De acordo com a autora, o ensino primário, em 1865, era dividido em primeiro grau, que corresponde à instrução elementar, e segundo grau, que acrescentava rudimentos das ciências à formação inicial.

Nesse contexto, o currículo se organizava em cinco disciplinas no primeiro grau, dentre as quais destacamos a que se relaciona ao ensino de língua materna, intitulada "Leitura e Escrita e noções de gramática Nacional" (BRITTO, 2005, p. 38). Entretanto, apesar de observarmos que o foco da Língua Portuguesa se direcionava ao ensino da leitura, escrita e gramática, verificamos em documentos internos da "Directoria Geral de Instrução Pública de Pernambuco", de 1864, que, para um professor assumir as cadeiras do ensino do primeiro grau, era necessário realizar um exame de habilitação, de forma mais específica, uma prova de Grammatica cujas perguntas giravam em torno de elementos estruturais da língua, vejamos abaixo:

Prova Grammatica

1) O que são verbos nas línguas?

2) Qual é a melhor, mais clara e mais lógica classificação dos verbos?

3) O que é prosódia?

4) Como se dividem os sons fundamentais que constituem a base da pronuncia? (...) (PERNAMBUCO, Folha 207)

Os elementos acima expostos podem nos dar indícios da ênfase que era dada aos conhecimentos da gramática normativa. No entanto, era observado também que havia preocupações relativas ao desenvolvimento moral das crianças.

A valorização de um ensino de língua voltado para gramática e leitura de textos religiosos foi marcante. Podemos destacar, como exemplo, um documento intitulado de "Reorganização do Ensino Público em Pernambuco", de 1874, no qual o ensino primário nas escolas públicas compreendia quinze disciplinas, dentre as quais destacamos aquelas que se relacionavam ao ensino de português:

(...) 1. Leitura e escripta; 2.Elementos de grammatica nacional. (...) 6. Leitura de Evangelhos e história sagrada; (...) Título III. Seção I Art. 33 (PERNAMBUCO, 1974, p.21)

Tal tendência também foi reportada por Chartier (2007), ao tratar do ensino da língua materna na França. A pesquisadora analisou manuais de ensino do francês e relatou que os manuais dos anos $1830-1850$ ora se referiam

a uma prática religiosa (as preces católicas) ora se destinavam à instrução, fossem eles religiosos, morais (sobre os deveres das crianças para com Deus, para com seus pais ou seus mestres), ou científicos (sobre o céu, os planetas, a terra, o mar, as plantas, os animais), ora tratavam de anedotas ou de pequenas narrativas da vida infantil (CHARTIER, 2007, p. 72) .

Já no documento intitulado "Regimento das Escolas de Instrução Primária", de1885, podemos constatar uma articulação dos eixos na estrutura da disciplina estruturada como "II Língua Nacional - leitura, recitação, exercícios grammaticaes práticos, redacção e composição". (p. 19) Ainda nesse documento, encontramos um "Plano Gradual de Ensino Primário", no qual, embora o foco de ensino fosse voltado para leitura e escrita, verificamos 
que a ênfase dada era à arte do bem escrever, conforme a literatura clássica, tal como nos conteúdos listados abaixo para o ensino da disciplina Língua Nacional no segundo grau:

Leitura corrente e explicada; exercícios de linguagem. Regras grammaticaes deduzidas de trechos clássicos, prática de redacção e composição com elementos dado pelo professor. Recitação de pequenas fábulas, trechos seletos de poesia. Noticia das principais obras clássicas, dada em conversação pelo professor (PERNAMBUCO, 1885, p.21).

Em documentos como de "Instrucção Primária", de 1928, constatamos que a leitura e escrita são trabalhadas na disciplina Leitura e Língua Nacional, sendo a concepção que subjaz a proposta curricular voltada ao estudo da estrutura da língua, conforme a lista de conteúdos no exemplo abaixo:

\author{
Leitura e Língua Nacional \\ $1^{\circ}$ classe \\ Leitura diária do livro adoptado, attendendo-se logo, quanto possível, à regra \\ de pronnucia e à inflexão da voz; \\ Graphia no quadro negro das palavras mais difícies e das expressões novas \\ (...) \\ Exercitar a classe no conhecimento de diphtongo e triphthongo, grupos \\ consonantaes, numero de syllabas de uma palavra: das palavras simples e \\ compostas, primitivas e derivadas. \\ Escripta \\ Continuação dos exercícios dados na classe infantil (...) \\ Cópias de sentenças. \\ Dictado de pequenas sentenças. \\ Formar pequenas pharares com elementos dados pelo professor (...) \\ (PERNAMBUCO, 1928, p. 11)
}

$\mathrm{Na}$ década de 1930, encontramos documentos específicos da época que listavam os objetivos e conteúdos a serem trabalhados nas diversas etapas da escolaridade. Nesse sentido, destacamos o documento intitulado "Programa de Educação Primária", apresentado pela Diretoria Técnica de Educação, em 1934. Neste, os objetivos de ensino de língua eram estabelecidos por meios da disciplina "meios de expressão e atividades manuais", nos diferentes anos, tais como:

$1^{\circ}$ Dar aos alunos possibilidades de associar sentenças e palavras escritas aos significados das mesmas; $2^{\circ}$ Habituá-los a articular com clareza e precisão as palavras lidas; (...) $4^{\circ}$ Desenvolver-lhes a disciplina do pensamento por todos os meios oportunos e aconselháveis. (...) (PERNAMBUCO, 1934, p.5)

Dado o exposto, podemos perceber que o ensino de Língua Portuguesa estava voltado para o desenvolvimento do pensamento, por meio de um trabalho articulado com a estruturação de frases, sendo estas o objeto central do ensino. Em outros termos, os conteúdos da disciplina "meios de expressão e atividades manuais", do primeiro ao quarto ano, resumiam-se a atividades como cópias, ditados, preenchimento de sentenças, tal como podemos observar no exemplo abaixo: 
Conversação generalizada sobre as causas e fatos do próprio mundo

dos alunos.

Visualização de sentenças curtas e simples (...).

Exercícios de visualização.(...)

Cópia, a lápis de cor, de sentenças em cadernos feitos pelos alunos.

Uso do livro de leitura, em momento oportuno. (...)

Representação de memória de todas as sentenças e palavras

visualizadas;

Escrever com clareza, o nome, o endereço, o lugar e a data do nascimento (...)

Substantivo: gênero e número. O ponto final e de interrogação.

(PERNAMBUCO,1937)

Segundo Britto (2005), nas décadas de 1950/60, vários programas mínimos de ensino, desenvolvidos nas diversas unidades escolares do estado e diferentes períodos do ano letivo, foram criados com o intuito de elaborar um produto final intitulado de "Programa de Ensino para o Curso Primário Infantil", publicado em 1961. Como a disciplina "linguagem" era norteada pelos eixos de ensino: leitura, escrita e gramática, podemos destacar alguns objetivos gerais de cada uma:

\footnotetext{
Leitura

Manter no aluno um interesse profundo e permanente pela leitura, firmandolhe a noção de utilidade da mesma, através da vida (...)

Desenvolver a habilidade de ler com compreensão procurando sempre interpretar o que fôr lido. Ampliar o campo de leitura do

aluno (...) Estimular o gosto pela boa literatura despertando o interêsse dos alunos pelo estudo da língua pátria e pela literatura

nacional, fortalecendo-lhe corretamente o sentimento de brasilidade.(p.3)

Escrita

Levar a criança a adquirir maior capacidade de organizar mentalmente o pensamento e de exprimi-lo por escrito, com simplicidade, clareza e correção, sob várias formas - correspondência, relatório, descrição, composição, narração, exposições de fatos, atas, requerimentos, etc. (p.8)

Gramática

O objetivo final do ensino de gramática é assegurar, no curso complementar, a formação de uma atitude favorável ao estudo das noções gramaticais básicas. (PERNAMBUCO, 1961, p.12)
}

Com os objetivos acima expostos, verificamos a preocupação da proposta em desenvolver o gosto pela leitura, principalmente, para a literatura nacional brasileira, como também o estímulo da leitura para diversas finalidades e utilidades práticas. Assim, observamos que, ao mesmo tempo em que atribui à literatura nacional um papel de destaque, não descarta a possibilidade de ampliação da leitura por meio de outros tipos de textos não literários. Já em relação à escrita, constatamos que, apesar do foco se direcionar à produção de alguns gêneros (relatório, requerimentos) ou para um trabalho com sequências discursivas (narração, descrição, exposição), encontramos também implicações oriundas da ênfase no desenvolvimento da capacidade de escrever conforme organização do pensamento no objetivo relacionado à escrita, acima citado. Essa noção de escrita se veicula à arte de dominar as regras gramaticais a fim de escrever corretamente, tal como é retratado nos objetivos mais específicos desse eixo: 
Tornar a criança sensível às incorreções da linguagem; Despertar-lhe o desejo de falar e escrever corretamente ou capacitá-la a descobrir e corrigir os próprios defeitos da linguagem. (PERNAMBUCO, 1961, p. 14)

Ainda na década de 1960, foi elaborado outro Programa de Ensino, o documento intitulado "Currículo da Escola Primária em Pernambuco", cujo enfoque era uma organização de uma proposta por níveis, objetivando atender adequadamente o desenvolvimento das capacidades dos alunos. O programa do Curso Primário possuía seis níveis e possibilitava que os alunos avançassem de acordo com o desenvolvimento de suas potencialidades. Os conteúdos eram abordados em nível crescente de dificuldade e complexidade. Segundo Britto (2005), o foco do trabalho com a linguagem nesse documento estava direcionado à "Gramática de maneira menos formal, dando mais relevo ao falar e escrever corretamente a língua pátria, diminuindo a preocupação com a aprendizagem de regras, definições e classificações" (BRITTO, 2005, p. 149).

Já na década de 1970, foi implementado oficialmente o tecnicismo e algumas reformulações a nível nacional foram realizadas. A organização do ensino no Brasil passava a ser subdividida em primeiro grau e segundo grau. Nesse contexto, os conhecimentos de Língua Portuguesa se constituíam na matéria intitulada "Comunicação e Expressão". Em Pernambuco, a Proposta Curricular de Ensino - $1^{\circ}$ grau, publicada em 1978, se constituiu inicialmente nos documentos: Volume I - Fundamentação fillosófica, socioeconômica cultural e psicológica; Volume II - Comunicação e Expressão; Volume III - Ciências incluindo Matemática e Volume IV - Estudos Sociais. Essa proposta materializava a concepção de língua como instrumento de comunicação, atendendo às exigências das orientações nacionais. Segundo Louzada (1998, p. 47), “com a edição da LDB, em 1971, a disciplina passou (...) a integrar o núcleo comum do currículo do $1^{\circ}$ Grau e a chamar-se Comunicação e Expressão".

Na década de 1990, o documento "Coleção Professor Carlos Maciel: subsídios para a prática pedagógica" foi proposto pela Secretaria Estadual de Educação e Cultura. Nessa, vinte e quatro documentos estavam direcionados ao Ensino Fundamental e Médio e tinham como objetivo suscitar reflexões para esses níveis de ensino. No que se refere ao ensino da Língua Portuguesa, destacamos o volume vinte e três que, além de representar "o empenho em trazer à discussão questões teóricas e práticas fundamentais sobre o ensino da Língua" (PERNAMBUCO, 1991, p.7), destaca sua especificidade, cuja pretensão é "acentuar a orientação do ensino da língua para a comunicação" (PERNAMBUCO, 1991, p. 7).

Ainda nesse documento, podemos observar que toda sua proposta curricular está articulada a uma forma de aquisição e aprendizagem funcional da língua ao enfatizar que "o núcleo maior da presente proposta é a concepção funcionalista da língua, da qual se deriva o princípio geral de que a língua só atualiza através dos textos, a serviço da comunicação intersubjetiva, em situações de atuação social” (PERNAMBUCO, 1991, p. 17).

Com o exposto, podemos observar que a concepção de língua se volta às práticas sociais em que o texto assume um papel de destaque. Com a intenção de romper com as concepções de língua como sistema abstrato, a proposta da "Coleção Professor Carlos Maciel" assume que "somente uma concepção funcionalista da linguagem pode, de forma ampla e legítima, fundamentar um ensino da língua que seja individual e socialmente produtivo e relevante" (PERNAMBUCO, 1991, p. 17).

Nesse sentido, o documento supracitado destina duas páginas ${ }^{1}$ para discutir concepções que norteiam as práticas do ensino do Português, mostrando ao leitor as

\footnotetext{
${ }^{1}$ Páginas 14 e 15 - ANEXO 1.
} 
implicações de um ensino mecânico, descontextualizado e centrado nas estruturas da língua. Nesse sentido, observamos a preocupação da proposta em não só apresentar argumentos que justifiquem a não adoção de "velhas tradições" no ensino de língua materna. Em outros termos, a mesma utiliza estratégias de leitura que tecem argumentos ao leitor que justifiquem a perspectiva a ser adotada para um ensino de língua materna dissonante do que, até então, vinha sendo proposto, ou seja, uma aprendizagem que fosse focada na estrutura da língua, suas normas e exceções, bem como suas aplicações nos diferentes eixos de ensino.

Assim, verificamos a intenção da "Proposta Professor Carlos Maciel: subsídios para a prática pedagógica" em se opor à perspectiva acima discutida, propondo a adoção de "princípios teóricos capazes de sustentar um ensino produtivo da língua" (PERNAMBUCO, 1991, p. 16).

Dessa forma, nas orientações destinadas aos conteúdos, o programa para as aulas de Português, em termos gerais, seria:

- falar,

- ouvir,

- ler e

- escrever textos em língua portuguesa, dentro de uma distribuição e complexidade gradativas, atendendo-se ao desenvolvimento conseguido no domínio de cada habilidade. Mais uma vez, explicitamos o princípio de que toda atividade linguística é necessariamente textual e, assim, é no texto e para o texto que se deve centrar o estudo relevante e produtivo da língua. (PERNAMBUCO, 1991, p. 29)

Com o exposto, podemos perceber que a ênfase no texto nos diversos eixos de ensino se constituía como numa preocupação para o ensino da língua portuguesa. Ainda nessa proposta, constatamos orientações para o desenvolvimento das habilidades de falar e ouvir, escrever e ler, no item "os conteúdos programáticos", tais como:

Falar e ouvir:

- contar histórias, reais ou imaginadas, inventando-as ou

reproduzindo-as;

- relatar acontecimentos;

- debater, discutir acerca dos temas variados (...) (PERNAMBUCO, 1991, p.29)

- [...]

Escrever:

- avisos aos colegas;

- $[\ldots]$

- convites;

- lista de cooperadores, de aniversariante, de materiais, de livros

[...]

- cartas, uns aos outros, aos professores, às pessoas da escola (...)

- esquemas, resumos, (...)

- pequenas narrativas (criadas ou recriadas a partir de outras lidas ou ouvidas)

- $[\ldots]$

- poemas;

- cartazes (...) (PERNAMBUCO, 1991, p.30) 
Ler

- historinhas, com ou sem gravuras e em quadrinhos (incluindo, é

claro, pequenas narrativas de caráter literário)

- poemas (apropriados à faixa etária dos alunos)

- $[\ldots]$

- notícias de jornal;

- folhetos;

- cartazes; (...) (PERNAMBUCO, 1991, p. 31-32)

Sendo assim, percebemos a grande preocupação da proposta em diversificar o material textual nos diversos eixos de ensino, reforçando a necessidade de ensinar a língua materna a partir dos textos. Nessa perspectiva, a diversidade textual é inserida na proposta nos eixos de ensino de língua portuguesa com o propósito de não só aproximar a língua dos diversos contextos e usos, mas também se contrapor a uma perspectiva descontextualizada da leitura e escrita na qual, segundo o documento supracitado, "o importante é que deixe a escrita vazia de palavras soltas, de frases soltas, que não dizem nada do mundo, da experiência e da fantasia das crianças" (PERNAMBUCO, 1991, p. 31).

Ainda em relação a essa diversidade textual, encontrada nas orientações para os conteúdos programáticos de Português, observamos que não são elencados apenas tipos de textos, mas também uma mistura entre gêneros (poema, convites, notícias, etc), tipos (desenvolvimento de pequenas narrativas) e portadores (cartazes). Observamos também que o item "conteúdos programáticos" apresenta confusões entre conteúdos e objetivos/habilidades, ou seja, nas indicações para o ensino para o desenvolvimento da habilidade de falar, ouvir, ler e escrever textos, podemos encontrar conteúdos a serem trabalhados tal como: "a escrita de pequenas informações aos pais" ou habilidades a serem desenvolvidas "a capacidade de emitir opiniões".

Assim, como vimos discutindo, constatamos que a principal preocupação da proposta "Professor Carlos Maciel: subsídios para a prática pedagógica" era evidenciar mudanças no que concerne à concepção de linguagem. Para tal, enfatizava a negação do ensino da língua como estrutura. Nesse sentido, o próprio eixo de ensino "gramática" está voltado para um estudo natural no texto, ou seja, se estudar a gramática numa "perspectiva eminentemente textual de forma a perceber como as categorias e regras gramaticais, na verdade, funcionam na construção dos textos, orais e escritos, curtos e longos" (PERNAMBUCO, 1991, p. 34). Reinou, então, nesta fase da história de Pernambuco, a perspectiva funcionalista, que no Século XXI passou a ser questionada.

\section{Algumas reflexões...}

Com base no que foi acima discutido, podemos observar que, em várias propostas curriculares, a linguagem era concebida como expressão de pensamento e, portanto, a ênfase recaía sobre a necessidade de aprender as regras gramaticais. Assim, era de extrema relevância um trabalho voltado para o ensino de frases fragmentadas, de elementos estruturais da língua, uma vez que o objetivo era o domínio da arte do escrever bem segundo as normas gramaticais. Com o advento de uma perspectiva mais utilitária da linguagem, as proeminências dos tipos textuais ganham espaço no ensino de língua materna, passando a ser vinculadas aos aspectos relacionados à apreensão de macroestruturas que definem o tipo textual. Em outros termos, a preocupação maior das orientações prescritivas incidia, muitas vezes, sobre o repasse do conhecimento das configurações textuais típicas, tais como narração, descrição, dentre outras. Por fim, vemos um discurso mais voltado ao uso de uma 
grande diversidade textual para o desenvolvimento das habilidades do aluno, através de uma ampla variedade de textos que circulam socialmente. Ou seja, de acordo com essa perspectiva, o contato com uma gama de textos, possibilitaria o desenvolvimento de capacidades necessárias ao reconhecimento de determinados textos e seus efeitos de sentido. Enfim, o texto era utilizado a serviço da comunicação, cuja ênfase dava-se no contato amplo de produção e recepção de texto. Não havia, no entanto, nos documentos daquela época, reflexões sobre as relações de poder que permeiam a linguagem e seus usos e nem discussão sobre o trabalho mais centrado nos gêneros textuais, temas que começam a desestabilizar as formulações da época.

Dessa forma, podemos observar que toda proposta curricular tem subjacente uma determinada concepção de linguagem. Assim, os elementos que a compõe, objetivos do ensino, conteúdos, orientações metodológicas, sugestões de atividades, perpassam por uma escolha de como conceber a língua, sua aquisição e sua aprendizagem. Nessa perspectiva, nada do que se concretiza nos textos prefigurativos ao longo da história deixa de se relacionar a um corpo de princípios, a partir do qual se percebem os fenômenos linguísticos e discursivos.

\section{Referências}

BAKHTIN, M. Estética da criação verbal. 3 ed. São Paulo: Martins Fontes, 2000.

BARDIN, L. Análise de Conteúdo. $3^{\text {a }}$ ed. Lisboa: Edições 70, LDA, 2004.

BRITTO, M. L. A trajetória do Currículo de Ensino Fundamental na Rede estadual de Pernambuco nos séculos XIX-XX - Aproximações do texto e do contexto. Recife: Editora Universitária da UFPE, 2005.

CHARTIER, A. M. Práticas de leitura e escrita: história e atualidade. Belo Horizonte: Autêntica, 2007.

CORDEIRO, S. G. Leituras possíveis no IDS: Agir, produção de textos e trabalho. In: GUIMARÃES, A. M. de M. et al (Orgs.). O interacionismo sociodiscursivo: questões epistemológicas e metodológicas. Campinas: Mercado das letras, 2007, p. 65-76.

MARINHO, M.; CARVALHO, G. T. A língua portuguesa nos currículos brasileiros. Revista Presença Pedagógica. Belo Horizonte: Dimensão, p. 41-53, jan/fev 1996.

A Língua Portuguesa nos currículos de final de século. In: BARRETO, E. S. de S. (Org.). Os currículos do ensino fundamental para escolas brasileiras. São Paulo: Autores Associados. Fundação Carlos Chagas, 1998 (Coleção Formação de professores).

PERNAMBUCO. Instrução Pública. Directoria Geral de Instrução Pública de Pernambuco de 1864. Folha 207 APJE. Pernambuco.

Documentos internos da Directoria Geral de Instrução Pública de Pernambuco, 1864. APJE. Pernambuco. 
Reorganização do Ensino Público em Pernambuco. Recife. Typ. de M. Figueirôa de F. \& Filhos, 1874. APJE. Pernambuco.

Regulamento orgânico da administração do ensino público (Reorganização da Instrução Publica Provincial). Recife: Typ de Manoel Figuerôa de Farias \& Filhos, 1879. APJE. Pernambuco.

Regulamento orgânico da administração do ensino público, da inspeção de ensino; dos funcionários a quem incumbe a inspeção, do inspetor geral, 1884. APJE. Pernambuco

Instruçção Primaria. Programma de ensino para os jardins de infância, classes infantis e demais classe do curso primário. Recife: Imprensa Official, 1928. APJE. Pernambuco.

Pernambuco.

Programa de Educação Primária. Recife: Imprensa Official, 1934. APJE, Pernambuco.

Programas de Educação Primária. Departamento de Educação, 1937. APJE. Programas de Ensino para curso Primário. Instituto de Pesquisas Pedagógicas, 1961. APJE. Pernambuco.

- Subsídios para a organização da prática pedagógica nas escolas. Língua Portuguesa - Da $1^{\mathrm{a}}$ a $4^{\mathrm{a}}$ série do Ensino Fundamental. Recife: SECE (Coleção Professor Carlos Maciel), 1991.

SOARES, M. Concepções de linguagem e o ensino de Língua Portuguesa. In: BASTOS, N. B. (Org.). Língua Portuguesa: História, Perspectivas, Ensino. São Paulo: Educ, 1998. p. 5360.

Alfabetização e letramento. São Paulo: Contexto, 2003.

TRAVAGLIA, L. C. Gramática e interação: uma proposta para o ensino de gramática do $1^{\circ} \mathrm{e}$ $2^{\circ}$ grau. São Paulo: Cortez, 1996.

Recebido em: outubro de 2013.

Aprovado em: março de 2014. 